\title{
FAMILY PHYSICIANS' MANAGEMENT OF GENETIC ASPECTS OF A CARDIAC DISEASE: A SCENARIO-BASED STUDY FROM SLOVENIA
}

\author{
Klemenc-Ketiš $\mathrm{Z}^{1,2, *}$, Peterlin $\mathrm{B}^{3}$
}

*Corresponding Author: Assistant Professor Zalika Klemenc-Ketiš, M.D., Ph.D., Medical Faculty Maribor, Taborska 8, 2000 Maribor, Slovenia. Tel.: +386-41-516-067. Fax: +386-590-30-250. E-mail: zalika.klemenc.ketis@gmail.com

\begin{abstract}
The aim of this study was to find out how Slovenian family physicians (FPs) would manage a hypothetical clinical case, to explore their views about possible ethical dilemmas associated with this clinical case and to determine possible associations with demographic and other characteristics of FPs. This was an observational cross-sectional postal study in the Slovenian FPs' surgeries. The study population consisted of the whole population of Slovenian FPs $(n=950)$. The main outcome measures were the percentages of the answers of FPs on different questions about the clinical case on the management of patient and his relative with hereditary cardiomyopathy.

There were 271 FPs who answered the questionnaire (response rate was 27.1\%). A sample included $66(24.4 \%)$ men and the mean age of all respondents was $45.5 \pm 10.6$ years. When dealing with the clinical case, most FPs expressed willingness to take the patient's family history. Only $34.2 \%$ FPs did not believe that ordering genetic tests was part of their job. Additionally, only $50.0 \%$ of them felt competent to interpret the genetic risk, $25.0 \%$ of them would give information about genetic testing and only $6.0 \%$ would interpret the results of the genetic testing.
\end{abstract}

\footnotetext{
${ }^{1}$ Department of Family Medicine, Maribor Medical School, 2000 Maribor, Slovenia

${ }^{2}$ Department of Family Medicine, Ljubljana Medical School, 1000 Ljubljana, Slovenia

${ }^{3}$ Clinical Institute of Medical Genetics, University Medical Center, Ljubljana, Slajmerjeva 3, 1000 Ljubljana, Slovenia
}

Family physicians in Slovenia were willing to include genetic tasks into routine management of their patients, but they do not feel competent enough to interpret the genetic risks and the results of genetic testing. However, an important part of FPs would not refer patients at risk to genetic counseling. The inclusion of genetic topics to family medicine specialization curriculum is needed.

Keywords: Case management; Family medicine; Genetics.

\section{INTRODUCTION}

Preventive activities are an important part of patient management at primary health level. Taking into account the effect of family and society when dealing with individual patients is also one of the core competencies of family medicine [1]. In the era of rapid evolvement of genetic medicine, family physicians (FPs) increasingly face the activities and dilemmas associated with the management of genetic aspects of disease and prevention [2].

Genetics is rarely taught at the undergraduate and postgraduate level of medical education of non genetic specialities [3]. It has already been shown that FPs had low confidence in their ability to carry out basic medical genetic tasks [4] but were aware of their need for additional education and even expressed their educational needs [5].

Even though family history is a crucial part of patient management in family medicine, its association with possible genetic background of disease develop- 
ment and higher disease risk is not yet fully used in practice $[6,7]$. Traditionally, family history taking is focused on the patients with symptoms or problems, which might imply that the patient is having a higher risk for the development of some chronic diseases, such as diabetes, coronary disease or asthma [8]. Healthy patients or patients' relatives are rarely being asked about their family history [9] Also, FPs very rarely decide to refer patients at risk to clinical genetics [10].

Family physicians regularly face ethical dilemmas in their everyday practice [11] and find the management of some of them quite difficult [12]. Genetic medicine is undoubtedly associated with many ethical dilemmas [13]. Similarly, many dilemmas can also be encountered when performing preventive activities such as screening for some diseases [14]. Therefore, the field of genetics in preventive activities performed in patients and their healthy relatives is a very sensitive area. Combined with the lack of knowledge of genetics [15], the FPs may face serious difficulties and doubts, and may feel reluctant to perform such activities even though genetic concepts are clearly part of current FPs practice in form of clinical decision making based on family history $[16,17]$. This was also shown in a clinical case scenario-based study with more than $60.0 \%$ of FPs who were willing to take family history but only $16.0 \%$ willing to order a genetic test
[18]. Similarly, primary care providers seem to assess breast cancer risk mainly by family history but rarely discuss genetic testing with the patients [10].

In Slovenia, as in many other European countries [3], genetic medicine is taught at the undergraduate level. However, it is not taught as a part of family medicine specialization curriculum [19]. The aim of this study was to find out how Slovenian FPs would manage a hypothetical clinical case and to explore their views about possible ethical dilemmas associated with this clinical case.

\section{MATERIALS AND METHODS}

Study Design. This observational cross-sectional postal study was conducted in Slovenia. It was approved by the Slovenian Ethics Committee (No. 40/09/12).

Participants. All Slovenian FPs were invited to participate in the study. According to the internal data of the Slovenian Medical Chamber (membership is obligatory for all Slovenian physicians), there were 950 working FPs in Slovenia at the time of the study.

Data Collection. We collected data by a postal survey sent in March 2013. The mail consisted of the questionnaire (described below), the invitation letter, and a pre stamped return envelope.

Table 1. Demographic and professional characteristics of family physicians in a sample.

\begin{tabular}{|l|c|c|}
\hline Characteristic & $\begin{array}{c}\text { Number of } \\
\text { Family Physicians }\end{array}$ & $\begin{array}{c}\text { Percentage of } \\
\text { Family Physicians }\end{array}$ \\
\hline Males & 66 & 24.4 \\
Females & 205 & 75.6 \\
\hline Education: & & 79.7 \\
family medicine specialist & 216 & 18.5 \\
family medicine resident & 50 & 1.5 \\
specialist in other fields & 4 & 0.4 \\
\hline without any specialization & 1 & 41.8 \\
\hline Involved in education of students and/or residents & 112 & 14.4 \\
\hline Education in genetics: & & 81.5 \\
$\cdot$ none & 39 & 2.2 \\
genetic content during undergraduate studies & 220 & 0.4 \\
genetic content in specialist training & 6 & 1.5 \\
\hline genetic content in courses & 1 & 18.1 \\
\hline genetic content in postgraduate studies & 4 & 32.5 \\
\hline Number of inhabitants living in practice catchment area: & & 23.2 \\
.$\quad$ less than 5000 & 49 & 25.8 \\
\hline 5000-20,000 & 88 & 63 \\
\hline 20,000-100,000 & 70 & \\
\hline
\end{tabular}


We used the internationally validated $[4,5,18,20]$ questionnaire that was developed as a part of the European Union (EU) project "Genetic Education, Improving Non-Health Professionals Understanding of Genetic Testing (EU 5th framework research - GenED)." First, the questionnaire was translated into the Slovenian language by two independent experts who agreed on its Slovenian version. Two independent experts then translated it back into the English language. Finally, both experts agreed on the final version of the Slovenian questionnaire.

The questionnaire consisted of the demographic questions (see Table 1) and questions about previous attendance to genetic education (see Table 1), of the scenario of clinical case and the questions on how to manage it, of the questions about the use of genetic knowledge in everyday management of patients, of the questions on the educational needs of FPs and of the questions on the self-perceived importance of providing genetic tests' information (see Tables 2 and 3). In Table 2, items 1-9 could be answered with the following options: family physician, cardiologists, genetic specialist. We dichotomized the answers into two categories: family phy- sician/other for the purpose of statistical analysis. In Table 3, items 10-18 could be answered with most likely, likely, unlikely and no. Again, we dichotomized the answers into two categories: yes/no, including most likely and likely to "yes" and unlikely and no to "no". Only the data on the management of patients described in the scenario and its associations with demographic and other characteristics of FPs are reported in this article.

The Scenario of a Clinical Case. Mr. Smith (aged 35) came to your surgery because his 27-yearold brother, a competitive swimmer, has just died suddenly. He collapsed in the pool and despite defibrillation was found to be dead. Although sudden death might not immediately suggest a genetic condition, Mr Smith is worried because his mother's sister died suddenly aged 30 and he asks whether the same may happen to him, his children Melanie (12 years), and Tom (6 months) or his brother (32 years). He has been told that his brother's postmortem demonstrated hypertrophic obstructive cardiomyopathy, which can be inherited as an autosomal dominant condition. Eighty percent of non traumatic sudden deaths in young athletes are due to in-

Table 2. Willingness of family physicians to carry out tasks related to the management of genetic patients in family medicine.

\begin{tabular}{|c|l|c|}
\hline$n$ & \multicolumn{1}{|c|}{ Task } & $\begin{array}{c}\text { Number (\%) of Family Physicians } \\
\text { Willing to Perform the Task }\end{array}$ \\
\hline 1 & Taking a family history & $200(73.8)$ \\
\hline 2 & Explaining the inheritance pattern & $136(50.2)$ \\
\hline 3 & Explaining the genetic risk to Mr. Smith's children & $73(50.2)$ \\
\hline 4 & Giving information about available genetic tests & $69(25.6)$ \\
\hline 5 & Informing Mr. Smith of the implication of no mutation being found & $50(18.5)$ \\
\hline 6 & Informing Mr. Smith of the implications of a mutation being found & $41(15.2)$ \\
\hline 7 & Ordering the genetic test & $92(34.2)$ \\
\hline 8 & Explaining the test results & $17(6.3)$ \\
\hline 9 & Explaining the implications of the test results for Mr. Smith's children & $14(5.2)$ \\
\hline 10 & Tell Mr. Smith it is his responsibility to inform his brother & $193(76.0)$ \\
\hline 11 & Ask Mr. Smith to convince his brother that he should be tested & $130(51.0)$ \\
\hline 12 & Let Mr. Smith decide whether or not he wants to inform his brother & $83(34.0)$ \\
\hline 13 & $\begin{array}{l}\text { Ask Mr. Smith to advise his brother to see you or another family physician for counseling } \\
\text { about his genetic risk }\end{array}$ & $232(89.2)$ \\
\hline 14 & Refer Mr. Smith to a genetic specialist for advice on how to handle the situation & $193(74.2)$ \\
\hline 15 & Refer Mr. Smith to a cardiologist for advice on how to handle the situation & $179(71.6)$ \\
\hline 16 & Respect Mr. Smith's wish not to inform his bother & $85(34.1)$ \\
\hline 17 & Offer to contact Mr. Smith's brother to inform him & $238(91.2)$ \\
\hline 18 & On his next visit inform the brother who is a patient and attends your practice & $190(73.9)$ \\
\hline
\end{tabular}


Table 3. Association between willingness of family physicians to carry out tasks related to the management of genetic patients in family medicine and some demographic and professional family physicians' characteristics.

\begin{tabular}{|c|c|c|c|c|c|c|c|c|c|c|c|c|}
\hline \multirow[t]{2}{*}{\begin{tabular}{|c} 
Task \\
(see \\
Table 2)
\end{tabular}} & \multicolumn{2}{|c|}{ Gender } & \multicolumn{2}{|c|}{ Age (years) } & \multicolumn{2}{|c|}{ Genetic Education } & \multicolumn{2}{|c|}{$\begin{array}{c}\text { Specialist of } \\
\text { Family Medicine }\end{array}$} & \multicolumn{2}{|c|}{$\begin{array}{l}\text { Years from } \\
\text { Graduation }\end{array}$} & \multicolumn{2}{|c|}{$\begin{array}{c}\text { Working } \\
\text { Experience (years) }\end{array}$} \\
\hline & $\begin{array}{c}\text { M vs. F } \\
(\%)\end{array}$ & $p$ Value & $t$ Value & $p$ Value & $\begin{array}{c}\text { Yes vs. No } \\
(\%)\end{array}$ & $p$ Value & $\begin{array}{c}\text { Yes } v s . \text { No } \\
(\%)\end{array}$ & $p$ Value & $t$ Value & $p$ Value & $t$ Value & $p$ Value \\
\hline 4 & 24.2 vs. 26.0 & 0.872 & -2.040 & 0.042 & 27.4 vs. 25.6 & 1.000 & 24.1 vs. 31.5 & 0.296 & -2.054 & 0.041 & 0.001 & 1.000 \\
\hline 5 & 21.2 vs. 17.6 & 0.585 & -2.112 & 0.036 & 18.7 vs. 17.9 & 1.000 & 18.1 vs. 20.0 & 0.846 & -2.065 & 0.040 & -1.645 & 0.101 \\
\hline 11 & 59.7 vs. 48.2 & 0.144 & 3.112 & 0.002 & 49.8 vs. 60.0 & 0.280 & 52.7 vs. 44.2 & 0.282 & 2.823 & 0.005 & 2.925 & 0.004 \\
\hline 12 & 37.9 vs. 32.8 & 0.526 & -3.077 & 0.002 & 33.8 vs. 33.3 & 1.000 & 32.1 vs. 41.2 & 0.247 & -3.098 & 0.002 & -2.943 & 0.004 \\
\hline 14 & 90.6 vs. 88.8 & 0.818 & -2.139 & 0.033 & 76.9 vs. 57.9 & 0.017 & 72.3 vs. 81.5 & 0.221 & -2.154 & 0.032 & -2.486 & 0.014 \\
\hline 15 & 81.0 vs. 72.1 & 0.187 & -1.602 & 0.110 & 74.1 vs. 59.5 & 0.077 & 68.2 vs. 84.6 & 0.024 & -1.399 & 0.163 & -1.850 & 0.066 \\
\hline 16 & 25.8 vs. 36.9 & 0.124 & -3.634 & $<0.001$ & 33.0 vs. 41.7 & 0.344 & 31.5 vs. 44.9 & 0.093 & -3.584 & $<0.001$ & -3.562 & $<0.001$ \\
\hline 17 & 92.1 vs. 90.9 & 1.000 & 1.320 & 0.188 & 92.9 vs. 80.6 & 0.025 & 91.3 vs. 90.6 & 0.791 & 1.111 & 0.268 & 1.532 & 0.127 \\
\hline 18 & 86.2 vs. 69.8 & 0.009 & 4.626 & $<0.001$ & 74.5 vs. 69.4 & 0.542 & 76.3 vs. 64.0 & 0.105 & 4.568 & $<0.001$ & 4.453 & $<0.001$ \\
\hline
\end{tabular}

herited or congenital cardiovascular abnor-malities and hypertrophic cardiomyopathy (HCM) accounts for $40.0-50.0 \%$ of these. Genetic testing may lead to identification of patients at high risk for sudden death as early as 10 years of age. Treatment can be considered with implantable defibrillators or medication. Mr Smith has agreed to be tested and the inherited mutation has been found but he does not want to inform his brother.

Data Analysis. We analyzed the data by the Statistical Package for the Social Sciences (SPSS) version 13.0 (SPSS for Windows; SPSS Inc., Chicago, IL, USA). We performed the descriptive analysis. In the bivariate analysis, we used the independent $t$-test and $\mathrm{c}^{2}$ test. We set the limit for statistical significance at a $p$ value of $<0.05$.

\section{RESULTS}

There were 271 (27.1\%) FPs who completed the questionnaire, out of which 66 (24.4\%) were men and 205 (75.6\%) were women (Table 1). Mean age of the sample was $45.5 \pm 10.6$ years. Mean age of the men was $50.1 \pm 11.8$ and mean age of the women was 43.9 $\pm 9.7(p<0.001)$. Mean working period of the sample was $17.3 \pm 11.6$ years and mean time from graduation $19.6 \pm 10.9$ years. Mean number of patient seen by the FP in the previous week was $213.7 \pm 77.7$.

When dealing with the clinical case, most FPs expressed willingness to take Mr. Smith's family history. More than $70.0 \%$ of FPs would tell Mr. Smith that it was his responsibility to tell his brother about the genetic risk and almost $90.0 \%$ would tell Mr. Smith to tell his brother to come to see them. In the last case, more than $90.0 \%$ of FPs would inform Mr. Smith's brother about the risk by themselves (Table 2).

Younger FPs were more inclined to give the information to Mr. Smith $(t=-2.040, p=0.042)$. Similar associations were found regarding years from graduation $(t=-2.054, p=0.041)$. Younger FPs (and those with less working years) would also more likely respect the wish of Mr. Smith not to inform his brother about the mutation $(t=-2.112, p=$ $0.036 ; t=-2.065, p=0.040$; respectively). On the other hand, older FPs, FPs with more working years and with more time since graduation would inform Mr. Smith's brother on his next visit to the practice $(t=3.112, p=0.002 ; t=2.823, p=0.005 ; t=2.925$, $p=0.004)$. Similar findings were detected also in terms of association of age/years from graduation/ working experiences and respecting or disrespecting the patient's wish regarding his brother and referrals to clinical specialists (Table 3).

\section{DISCUSSION}

More than $70.0 \%$ of Slovenian FPs believe that taking family history is a part of their everyday job. On the other hand, up to $70.0 \%$ of them do not be- 
lieve that ordering and discussing genetic tests or their implications is part of their job. Additionally, only $50.0 \%$ of them feel competent to interpret the genetic risk, $25.0 \%$ of them would give information about genetic testing and only $6.0 \%$ would interpret the results of the genetic testing.

This is the first study on FPs' attitudes to genetic management of patients in Slovenia and also in the southeastern part of Europe. A study using the same questionnaire and also the same clinical case scenario was conducted in France, Germany, The Netherlands, Sweden and the UK, and showed that $61.0 \%$ of FPs would take a family history but only $38.0 \%$ would explain an inheritance pattern and $16.0 \%$ would order a genetic test [18]. In our study, the percentages of FPs taking a family history are higher than in the previously mentioned European studies. Also, Slovenian FPs seem to be more willing to engage in other genetic activities (i.e., explaining the inheritance pattern, ordering a genetic test) than their colleagues from some European countries, even though the percentage of them willing to do so is still low. A similar study on the FPs' views on their role in cancer genetic services showed that $60.0 \%$ of them would take a detailed family history from the patient, almost $80.0 \%$ would decide which patients should be referred to genetics clinic and a quarter of them would counsel the patient on cancer risk [21]. It seems that FPs were willing to engage in genetic activities but clearly distinguish between the routine use and function of family history in clinical decision making and contrasting conceptualizations of genetics and genetic conditions as shown by Mathers et al. [16]. Family physicians seem to be willing to embrace genetics as a part of their work from the aspect of core competencies of family medicine (comprehensive approach) and not from an isolated clinical genetics view. Nevertheless, they expressed a very strong opinion about family history taking as their task and we have to take into account that family history is a basic genetic tool $[22,23]$.

Each time a genetic test is undertaken by physicians or by patients themselves, its results will inevitably affect not only the life of the patients but also of their relatives. Confidentiality is one of the basic principles that have to be followed by any physician [24]. However, in some cases (i.e., a duty to warn relatives about risk of some infectious diseases or to warn public about an imminent harm) physicians are legally allowed to breach confidentiality. As far as the notification of family members of the identification of a genetic mutation by physicians is concerned, no clear answer yet exists [25]. It is an example of a conflict between the physician's ethical obligations to respect the privacy of genetic information and the potential liabilities resulting from the physician's failure to notify at risk relatives [26]. According to our study, FPs believe that it is the patients' responsibility to notify their relatives at risk and they would even encourage patients to do so. A majority of them would even offer to help them to inform their relatives. Similarly, UK physicians considered informing family members about genetic risk as a family responsibility [27]. Over two-thirds of medical geneticists in a the USA study [28], believed they should bear the responsibility of warning their patients' relatives when found to be at risk for genetic disease. However, only one quarter of those who faced the dilemma of a patient refusing to notify their at risk relatives seriously considered disclosure to those at risk relatives without the patient's consent [28]. In our study, almost 70.0\% of FPs would not respect the patients' wishes not to inform their relatives and would inform them by themselves when first seeing them in the practice. Clearly, FPs are not clear about the correct procedure of informing relatives about genetic risk but according to other studies, this is a wider problem which has not yet been solved [29].

The results of our study highlighted some differences regarding demographic and professional characteristics. The most obvious one was age. It seems that younger FPs were more willing to include genetic tasks into their everyday practice. Also, they appeared to be more sensitive to ethical issues. A study based on the same clinical case [18] showed some differences regarding gender: male FPs seemed to be more willing to perform genetic tests. In our study, male FPs were only found to be more inclined to inform Mr. Smith's brother about the genetic risk. Taking into account that similar associations as with age were found also regarding working years and years since graduation, the differences might be the consequence of the previous finding that the younger generation was more confident in their abilities about genetic tasks and have more genetic knowledge $[4,15]$. The older 
generation, on the other hand, usually did not want to change their steady management of patients. We also observed differences regarding education as the physicians with more genetic education and those with the family medicine specialization would be more willing to refer patients to genetic and/or cardiovascular assessment.

Greater sensibility of younger and more educated FPs could be the consequence of a new program of family medicine specialization, which also introduced ethical topics to the curriculum [19]. This was also shown by previous studies in Slovenia $[12,30]$. These findings indicate the need for the introduction of genetic topics to family medicine specialization curriculum.

This study was performed in a representative sample of Slovenian FPs and its findings can therefore be generalized to the whole population of FPs in Slovenia. The strength of this study is also the use of a previously validated questionnaire which gives us confidence in the reliability of data. This was a cross-sectional study so it is not possible to detect any causal relationship between variables. The response rate in this study was expected, as a $20.0 \%$ response rate is usual for postal surveys $[12,31]$. Nevertheless, it can be a source of selection bias. Also, the use of a theoretical clinical case represents simulated environment, thus in reality, physicians might have decided differently.

\section{CONCLUSIONS}

Family physicians in Slovenia seem to be willing to include genetic tasks into routine management of their patients but they do not feel competent enough to interpret the genetic risks and the results of genetic testing. However, a great percentage of FPs would not refer patients at risk to genetic counseling. Family physicians are aware of their duty of providing information in order to prevent harm but a great many of them would choose not to respect their patients' wishes regarding confidentiality issues.

Family physicians are in need of additional information on their role in genetic management of patients and clear guidelines on ethical issues. Further studies should be directed to the assessment of genetic knowledge in FPs, on the assessment of inpractice management of their patients in terms of genetic medicine and on deeper exploration of FPs' attitudes towards ethical issues associated with genetic medicine.

\section{ACKNOWLEDGMENTS}

We thank Metka Cerovič, M.D., Maribor Health Centre, Maribor, Slovenia, for her help in collecting the data and entering it into the computer program. We also thank all Slovenian FPs who took part in the study. This study was partially supported by an unrestricted program grant from the National Research Agency P3 0339. We thank the Slovenian Institute for the Development of Family Medicine for their financial support in data gathering.

Declaration of Interest. The authors report no conflicts of interest. The authors alone are responsible for the content and writing of this article.

\section{REFERENCES}

1. Allen J, Gay B, Crebolder H, Heyrman J, Svab I, Ram P. The European Definition of General Practice/ Family Medicine. Wonca Europe, 2011.

2. Acheson LS, Wiesner GL. Current and future applications of genetics in primary care medicine. Prim Care. 2004; 31(3): 449-460.

3. Challen K, Harris HJ, Julian-Reynier C, ten Kate LP, Kristoffersson U, Nippert I, et al. Genetic education and non genetic health professionals: educational providers and curricula in Europe. Genet Med. 2005; 7(5): 302-310.

4. Nippert I, Harris HJ, Julian-Reynier C, Kristoffersson U, ten Kate LP, Anionwu E, et al., Confidence of primary care physicians in their ability to carry out basic medical genetic tasks - A European survey in five countries-Part 1. J Community Genet. 2011; 2(1): 1-11.

5. Julian-Reynier C, Nippert I, Calefato JM, Harris $\mathrm{H}$, Kristoffersson U, Schmidtke J, et al. Genetics in clinical practice: General practitioners' educational priorities in European countries. Genet Med. 2008; 10(2): 107-113.

6. Guttmacher AE, Collins FS, Carmona RH. The family history - more important than ever. $\mathrm{N}$ Engl J Med. 2004; 351(22): 2333-2336.

7. Rich EC, Burke W, Heaton CJ, Haga S, Linsky L, Short MP, et al. Reconsidering the family his- 
tory in primary care. J Gen Intern Med. 2004; 19(3): 273-280.

8. Reid G, Emery J. Chronic disease prevention in general practice: Applying the family history. Aust Fam Physician. 2006; 35(11): 879-885.

9. Langlands AR, Prentice DA, Ravine D. A retrospective audit of family history records in shortstay medical admissions. Med J Aust. 2010; 192(12): 682-684.

10. Sabatino SA, McCarthy EP, Phillips RS, Burns RB. Breast cancer risk assessment and management in primary care: Provider attitudes, practices, and barriers. Cancer Detect Prev. 2007; 31(5):375-383.

11. Klemenc-Ketiš Z, Kersnik J. Prevalence of ethical dilemmas in Slovenian family practice. Acta Medico-Biotechnica. 2009; 2(2): 47-56.

12. Klemenc-Ketiš Z, Kersnik J, Ojstersek J. Perceived difficulties in managing ethical problems in family practice in Slovenia: Cross-sectional study. Croat Med J. 2008; 49(6): 799-806.

13. Rubinstein WS. Roles and responsibilities of a medical geneticist. Fam Cancer. 2008; 7(1): 5-14.

14. Getz L, Kirkengen AL, Hetlevik I, Romundstad S, Sigurdsson JA. Ethical dilemmas arising from implementation of the European guidelines on cardiovascular disease prevention in clinical practice. A descriptive epidemiological study. Scand J Prim Health Care. 2004; 22(4): 202-208.

15. Baars MJ, Henneman L, Ten Kate LP. Deficiency of knowledge of genetics and genetic tests among general practitioners, gynecologists, and pediatricians: A global problem. Genet Med. 2005; 7(9): 605-610.

16. Mathers J, Greenfield S, Metcalfe A, Cole T, Flanagan S, Wilson S. Family history in primary care: Understanding GPs' resistance to clinical genetics - qualitative study. Br J Gen Pract. 2010; 60(574): 221-230.

17. Carroll JC, Brown JB, Blaine S, Glendon G, Pugh P, Medved W. Genetic susceptibility to cancer. Family physicians' experience. Can Fam Physician. 2003; 49: 45-52.

18. Challen K, Harris H, Kristoffersson U, Nippert I, Schmidtke J, ten Kate LP, et al. General practitioner management of genetic aspects of a cardiac disease: A scenario-based study to anticipate providers' practices. J Community Genet. 2010; 1(2): 83-90.

19. Bulc M, Svab I, Pavlic DR, Kolsek M. Specialist training of Slovene family physicians. Eur J Gen Pract. 2006; 12(3): 128-132.

20. Calefato JM, Nippert I, Harris HJ, Kristoffersson U, Schmidtke J, ten Kate LP, et al. Assessing educational priorities in genetics for general practitioners and specialists in five countries: Factor structure of the Genetic-Educational Priorities (Gen-EP) scale. Genet Med. 2008; 10(2):99-106.

21. Fry A, Campbell H, Gudmunsdottir H, Rush R, Porteous M, Gorman D, et al. GPs' views on their role in cancer genetics services and current practice. Fam Pract. 1999; 16(5):468-474.

22. Yoon PW, Scheuner MT, Jorgensen C, Khoury MJ. Developing Family Healthware, a family history screening tool to prevent common chronic diseases. Prev Chronic Dis. 2009; 6(1): A33.

23. Scheuner MT, Raffel LJ, Larabell SK, Rotter JI. Family history: A comprehensive genetic risk assessment for chronic conditions of adulthood. Am J Med Genet. 1997; 71(3): 315-324.

24. Mencin Ceplak M, Hlebec V. Trust in an individual physician and its contradictions. Zdrav Var. 2012; 51(1): 53-68.

25. Gaff CL, Clarke AJ, Atkinson P. Process and outcome in communication of genetic information within families: A systematic review. Eur J Hum Genet. 2007; 15(10): 999-1011 (erratum in: Eur J Hum Genet. 2008; 16(3): 402).

26. Offit K, Groeger E, Turner S, Wadsworth EA, Weiser MA. The "duty to warn" a patient's family members about hereditary disease risks. JAMA. 2004; 292(12): 1469-1473.

27. Forrest K, Simpson SA, Wilson BJ, van Teijlinger ER, McKee L, Haites $\mathrm{N}$, et al. To tell or not to tell: Barriers and facilitators in family communication about genetic risk. Clin Genet. 2003; 64(4):317-326.

28. Falk MJ, Dugan RB, O'Riordan MA, Matthews AL, Robin NH. Medical geneticists' duty to warn at-risk relatives for genetic disease. Am J Med Genet A. 2003; 120A(3): 374-380.

29. Lucassen A, Parker M. Confidentiality and serious harm in genetics - preserving the confidentiality of one patient and preventing harm to relatives. Eur J Hum Genet. 2004; 12(2): 93-97. 
30. Klemenc-Ketiš Z, Ojstersek J, Kersnik J. Influence of specialistic training in family medicine on detection and management of ethical dilemmas. Zdrav Vestn. 2009; 78(4): 169-174.
31. Klemenc-Ketiš Z, Kersnik J. The assessment of pharmaceutical sales representatives by family physicians - does it affect the prescribing index? Fam Pract. 2012; 30(3): 320-324. 